\title{
Evaluation of antibiotic susceptibility of Staphylococcus aureus isolated from nasal and thumb prints of University students and their resistance pattern.
}

\author{
Emeka Lorina. Ineta ${ }^{\mathrm{a}},{ }^{*}$ Emeka Promise. Madu ${ }^{\mathrm{b}}$, Okoli, Chigozie. Linus. ${ }^{\mathrm{a}}$ \\ ${ }^{a}$ Department of Microbiology, Faculty of Biological Sciences, University of Nigeria, Nsukka. Nigeria. \\ ${ }^{b}$ Department of Pharmaceutical Sciences, College of Clinical Pharmacy, King Faisal University, AlAhsa \\ Kingdom of Saudi Arabia.
}

\begin{abstract}
Staphylococcus aureus has long been known as one of the most important bacteria that cause disease in humans. It may gain access to underlying tissues or the bloodstream and cause infection and it's a leading cause of skin and soft tissue infections such as abscesses. Colonization with S. aureus usually precedes an infection. The aim of this study was to investigate the prevalence of $S$. aureus carrier frequency among students community and to characterise the antibiotic susceptibility of the isolated organism. The frequency of S. aureus carriage among students from University of Nigeria, Nsukka was investigated. A total of 120 nasal swabs and thumbprint samples were collected from healthy microbiology and biochemistry students. All swabs were streak on mannitol salt agar (MSA); incubated at $37^{\circ} \mathrm{C}$ for $24 \mathrm{~h}$. Characterization of the bacterial isolates was based on standard microbiological methods. Antimicrobial susceptibility testing was also assayed in order to detect any antibiotic resistant $S$. aureus. Antimicrobial susceptibility of confirmed isolates was determined by disc-diffusion method. The results obtained showed that, 42(70\%) of microbiology students had Staphylococcus aureus colonization in both nasal and thumb. Also, 49 (81.66 \%) biochemistry students, had staphylococcus colonisation. Antibiotic susceptibility test of isolated S. aureus demonstrated a varying degree of resistance with the highest seen with $\beta$ lactam antibiotics. Amongst the $\beta$ lactam antibiotics, Cloxacillin showed the highest resistance with $100 \%$, while all the isolates were $100 \%$ susceptible to Gentamicin, $95 \%$ to Streptomycin.

This result shows the likelihood of a changing resistant pattern among the students community. The reasons could be multifactorial and warrants further investigation.

Key Words: Staphylococcus aureus, nasal, thumbprint, antibiotic susceptibility, resistance.
\end{abstract}

\section{Introduction}

Staphylococcus aureus is a non motile Gram-positive coccus frequently found as part of the normal skin flora, on the skin and nasal passages [1]. It is well established that at any given time, approximately $30 \%$ of all persons are colonized with S. aureus, with the anterior nares serving as its critical niche [1]. Previous reports identified the anterior nares as the most consistent site of staphylococcal colonization [2]. Although colonization typically precedes infection, relatively few colonized individuals develop staphylococcal infection Also von Eiff [3] reported that $S$. aureus infections occurred in persons who are colonized with the organism. There is undoubtedly a variety of host organism interaction that plays a role in this symbiotic relationship. However, much of what is known has been derived from the study of persons with clinical disease and not those in the asymptomatic carrier state. S. aureus is an important cause of human disease [2]. Although staphylococcal disease is most often associated with skin and soft tissue infections, its manifestations are myriad and include syndromes with low morbidity and mortality such as folliculitis, food poisoning and fatal systemic illness such as endocarditis and toxic shock [4]. The carriage of the bacterium has long been known to be one of the most strongly associated risk factors for subsequent infections as reported by various workers $[3,5,6]$. Nasal colonization by $S$. aureus can provide an indication of a higher risk for subsequent infection including MRSA [1]. It is still one of the most common causes of nosocomial infections as well as the cause of post surgical wound infections. It is recorded that some 500,000 patients in American hospitals contact a staphylococcal infection, every year [7]. A number of investigations have indicated that S. aureus is the main etiological agent of many infections in Nigeria by workers such as $[8,9,10,11,12]$. The infection ranges from superficial to deep septicaemia [13].

The aim of the present study was to investigate the prevalence of S. aureus carrier frequency among students community and also to characterise their antibiotic susceptibility. 


\section{Study Population}

\section{Methods.}

The study was carried out at the University of Nigeria, Nsukka, located in the Eastern region of Nigeria. One hundred and twenty (120) specimens consisting of sixty nasal swabs and sixty thumbprints were collected from students of two degree programmes in the university. The sample population comprised of 60 microbiology students and 60 biochemistry students of which each were divided into two groups of 30 each. The subgroups in each of the main groups were nasal and thumb samples respectively. The aim of the study and method was presented to the ethical committee of the university who approved the project. The willingness of the subjects to participate in the study was a strong criterion. The mean age of the participants was 23 of which $50 \%$ were females and $50 \%$ were males. The samples were collected randomly from the students present at the time of sample collection.

\section{Sample Collection}

A nasal swab from each student was collected by robbing over the anterior nares of both nostrils. The swabs were streak on mannitol salt agar (MSA), (Oxoid England). At the same time, the participants placed their thumbprint from the right hand, on another MSA plate. All plates were incubated at $37^{\circ} \mathrm{C}$ for $24 \mathrm{~h}$. Characterization of the bacterial isolates was based on standard microbiological methods [14]. Each distinctive morph type of mannitol-fermenting colony was selected from the MSA plate and sub-cultured on blood agar (Zayo Sigma, Germany) at $37^{\circ} \mathrm{C}$ for $24 \mathrm{~h}$. Incubated cultures on blood agar were screened using method described by Cowan and Steel [15].

\section{Identification of Isolates.}

All isolates were identified using routine laboratory procedures. The reaction to Gram stain, basic colonial morphology, cultural characteristics on MSA (i.e. reduced $\mathrm{pH}$ turned medium colour from red to yellow), reaction to catalase test, by the release of $\mathrm{O}_{2}$. Isolates that were Gram-positive cocci (grape-like cluster), positive to catalase test, and slide coagulase test (Staphytec plus, Oxoid Diagnostic Reagents) were considered as $S$. aureus [16].

\section{Antibiotic Susceptibility Testing.}

The disc diffusion method for in-vitro antibiotic susceptibility tests described by Bauer et al., [17] was adopted for the study. The concentrations of the antimicrobial sensitivity and the interpretation of zones of inhibition were performed according to the National Committee for Clinical Laboratory Standards [18]. The antibiotics (ABTEK, biological Ltd UK) included Augumentin (30ug), Streptomycin (10ug), Gentamicin (10ug), Cloxacillin (5ug), Cotrimoxazole (25ug), Tetracycline (25ug), Erythromycin (5ug) and Chloramphenicol (10ug).

The plates had been previously streaked with each of the bacterial isolates respectively and then incubated at $37^{\circ} \mathrm{C}$ for 24 hours. The presence of zone of inhibition around each of the disc after the period of incubation was regarded as the presence of antibacterial action while the absence is lack of measurable antibacterial action. The diameter of zone of inhibition produced by each antibiotic was measured.

\section{Statistical analysis}

Microsoft excel (2010) Chi test was used for comparisons between groups and the values were reported as mean/ percentages (\%) \pm standard deviation (SD).. Values with $P<0.05$ were considered to be significant.

\section{Results}

The results obtained show that out of sixty microbiology students sampled (i.e. 30 nasal and 30 thumbprint) 42(70\%) had Staphylococcus aureus colonization. Also, 49 (82\%) of biochemistry students sampled were seen to be colonization as shown in Table 1 . The difference between the two groups, was statistically not significant. In relation to gender, female participants were more (80\%) colonised than the males $(72 \%)$ and the difference was also statistically not significant $(\mathrm{p}=0.286)$. The results obtained from nasal and thumbprint colonization for both groups are presented in table 2. Staphylococcus aureus was isolated more from the nasal regions than from the thumbprint representing $80 \%$ and $87 \%$ respectively for both groups while thumbprint colonization was 60 and $70 \%$. The difference in percentage of nasal or thumbprint isolates for both groups were statistically not significant. Gender wise, all group 2 females (100\%) and $73 \%$ of females in group 1 were colonized and this colonization was variable as shown in table 3 also the difference was not statistically significant. Antibiotic susceptibility test demonstrated that $S$. aureus isolates were seen to be highly resistant to $\beta$ lactam antibiotics. Resistance was highest with Cloxacillin (100\%) followed by Augmentin at 93 and $90 \%$ for groups 1 and 2 isolates respectively. For other antibiotics, isolates were totally susceptible to Gentamicin and 
Streptomycin while very low resistance was observed against Erythromycin, Chloramphenicol and Tetracycline as shown in fig. 1.

The zones of antibiotic inhibition by the isolates from the study groups are presented in figures 2 and 3. The result shows that Gentamicin and Streptomycin produced the highest inhibitory zones. This was followed by Erythromycin for the group 1 (microbiology student). Thumbprint isolates of group 1 participants exhibited higher zones of inhibition than those which had been isolated from their nasal region as shown in Figure 3. A similar pattern was also observed with the biochemistry students with their thumbprint isolates showing higher zones of antibiotic inhibition than their nasal samples (fig.3).

Augmentin and Cloxacillin produced the least zones of inhibition amongst isolates from both groups.

\section{Discussion}

Staphylococcus aureus a common colonizer of the skin and nose has become one of the most successful adaptable human pathogens. The bacterium has been reported by various workers $[19,20,21]$ to have remarkable ability to acquire antibiotic resistance contributing to its emergence as an important pathogen in a variety of setting. In the present study, an overall prevalence of $76 \%$ colonization with $S$. aureus was obtained from the nasal and Thumbprints samples and most of the isolates were from the nasal region. This high level of colonization as seen in the present study could be because nasal regions have been reported to be the major reservoir of $S$. aureus [22, 23]. Similar findings had also been reported [2, 24]. A high percentage (50\%) of $S$. aureus nasal colonization in hospital and non-hospital subjects has been reported in previous studies [25]. However, Adesida et al., [26] reported a much lower (14\%) nasal colonization amongst medical students. This therefore suggests a variation that could be attributed to a number of factors such as geographical, characteristics and probably the level of education of participating subjects. Results from the present study were seen not to have been affected by gender and therefore did not differ in terms of sex of the participants. Despite the fact that all the females in group 2 were colonized by $S$. aureus, this was different for the group 1 participants, again suggesting that results are variable in distribution. The difference in colonization rates between the groups (microbiology and biochemistry students) was found to be statistically not significant. This therefore implies that $S$. aureus colonises healthy individuals irrespective of the sex or level of education. Similar isolation of $S$. aureus from students in a health institution has been reported by Marques et al., [16]. Nasal colonization did not mean that the thumbs would be colonized as was seen in the present study, agreeing with the fact that the nasal regions are the major reservoirs for the bacterium.

Antibiotic susceptibility test carried out on isolates from the present study showed high resistance to $\beta$ lactam antibiotics. All (100\%) of the isolates were resistant to cloxacillin and $96 \%$ to augmentin. This might be due to antibiotic misuse or abuse as suggested by other workers who reported that penicillins are the most misused antibiotics amongst Nigerian communities [27]. Furthermore Adegoke et al., [28] reported a $72 \%$ penicillin resistance on $S$. aureus isolates, thus presenting a worrisome situation as penicillin is still being used in the treatment of Staphylococcal infections. However others were of the view that this resistant S. aureus strains have emerged from the hospitals and spread to the community [29]. All of the isolates from the present study were sensitive to gentamycin and streptomycin. A high sensitivity to gentamycin has also been reported by other workers [16]. Gentamycin and streptomycin are less commonly used antibiotics. Gentamycin is a parenterally administered drug making it more difficult to misuse or abuse. The high resistance of isolates from the present study to commonly prescribed antibiotics demonstrate the urgent need for proper management of antibiotics use. Nigeria has a high rate of antibiotic misuse as well as high prevalence of self-medication use [30]. Studies have shown that misuse of antibiotics is a main cause of antimicrobial resistance [31, 32]. Therefore misuse and self-medication are factors identified as being responsible for the emergence of antibiotic resistant bacterial strains. Although there was a high sensitivity to gentamycin and streptomycin, the high cost of these drugs and its route of administration does not put them in the group of first choice of treatment or selfmedication.

The present findings therefore indicate the importance of investigating staphylococcal colonization of the nasal mucosa in order to ascertain the epidemiology, level of antibiotic susceptibility of $S$. aureus infection and thus develop intervention strategies/ preventive measures as well as treatment possibilities. More work is therefore suggested to address the changing resistance pattern within the community.

\section{Acknowledgements}

The authors wish to express their gratitude to the students who participated in this study for their contribution to the research. The authors would like to thank Biochemistry and Microbiology students in particular.

Ethical approval: University of Nigeria Nsukka and Faculty of Biological Sciences Ethics Committee.

Funding: None received.

Competing interests: None declare 


\section{References.}

[1]. Kluytmans J, Van Belkum A, Verbrugh H. Nasal carriage of Staphylococcus aureus: epidemiology, underlying mechanisms, and associated risks. Clin Micro Rev. 1997; (10):505-520.

[2]. Kuehnert MJ, Deanna K, Hill HA. Prevalence of Staphylococcus aureus Nasal Colonization in the United States. The Journal of Infectious Diseases. 2006; (193):172-179.

[3]. von Eiff C, Becker K, Machka K. Nasal carriage as a source of Staphylococcus aureus bacteremia. N Engl J Med. 2001; 344:11-16.

[4]. Lowry FD. Staphylococcus aureus Infection. New Engl. J. Med. 1998; 339: 520-532.

[5]. Clauditz A, Resch A, Wieland KP, Peschel A, Götz F. Staphyloxanthin plays a role in the fitness of S. aureus and its stability to cope with oxidase stress. Infection and immunity 2006; 74(8): 4950-3.

[6]. Liu GY,Essex A, Buchanan JT, Datta V, Hoffman HM, Bastian JF, Fierer J, Nizet V. Staphylococcus aureus golden pigment impairs neurtophil killing and promotes virulence through its antioxidant activity. Experimental Medicine 2005; 202: 209-15.

[7]. Chambers HF. The changing epidemiology of Staphylococcus aureus. Emerging Infectious diseases. 2001; 7 (2): 178-82

[8]. Anah MU, Udo JJ, Ochigbo SO, Abia-Bassey LN. Neonatal septicaemia in calabar, Nigeria. Trop. Doct. 2008; 38: 126-128.

[9]. Odetoyin WB, Aboderin AO,Ikem RT, Kolawole BA, Oyelese AO. Asymptomatic bacteriuria in patients with diabetes mellitus in Ile-Ife, South-West Nigeria. East African Journal of Medicine. 2008; 85: 18-23.

[10]. Adeleke SI and Asani MO. Urinary tract infection in children with nephritic syndrome in Kano, Nigeria. Annual African Medicine. 2009; 8: 38-41.

[11]. Bekibele CO, Kehinde AO, Ajayi BG. Upper lid skin bacterial count of surgical eye patients in Ibadan, Nigeria. African Journal of Medicine and Medical Sciences. 2009; 37: 273-277.

[12]. Onipede AO, Onayade AA, Elusiyan JB, Obiajunwa PO, Ogundare EO, Olaniran OO, Adeyemi LA, Oyelami OO (. Invasive bacterial isolates from children with severe infections in Nigerian hospital. J. Infec. Dev. Ctries. 2009; 2: 429-436.

[13]. Komolade AO and Adegoke AA. Incidence of bacterial septicaemia in Ile-Ife, Nigeria. Malasian J. Microbial. 2008; 4(2): 51-61

[14]. Dionigi R, Rovera F, Dionigi G, Imperatori A, Ferrari A, Dionigi P, Dominioni I. Risk factors in surgery. Journal of Chemotherapy. 2001; 13: 6-11.

[15]. Cowan ST, Steel KJ. In'Manual for identification of Medical Bacteria. 3rd Edition. Cambridge University Press 2004; 50-140.

[16]. Marques J, Barbosa J, Alves I, Moreira L. Staphylococcus aureus nasal and hand carriage among students from a Portuguese health school. British Journal of Biomedical Science 2010; 67(1): 5-8.

[17]. Bauer AW, Kirby WMM, Sherris JC, Turok M. Antibiotic susceptibility testing by standardized single disk method. Am. J. Clin. Pathol. 1996; 45: 493-496.

[18]. NCCL. National Committee for Clinical Laboratory Standards for antimicrobial disk susceptibility testing. Twelfth information supplement (M100 - S12) Wayne, PA: NCCL 2002.

[19]. David MD, Kearus AM, Gossain S, Ganner M, Holmes A (2006). Community - associated methicillin - resistant Staphylococcus aureus: nosocomial transmission in a neonatal unit. J. Hosp. Infect. 64: 244-250.

[20]. Sampathukumar P. Methicillin-Resistant Staphylococcus aureus: The latest Health Scare. Moyo Clin Proc. 2007; 82: 1403-1467.

[21]. Hotu B, Ellenbogen C, Hayden MK, Aroutcheva A, Rice TW, Weinstein RA. Community- associated methicillin-resistant Staphylococcus aureus skin and soft tissue infections at a publichospital: do public housing and incarceration amplify transmission? Arch. Intern. Med. 2007; 167: 1026-1033.

[22]. Appelbaum PC. Reduced glycopeptides susceptibility in methicillin-resistant Staphylococcus aureus (MRSA). Int J. Antimicrob. Agents. 2007; 30: 398-408.

[23]. Koziol-Montewka M, Szczepanok A, Baranowicz I, Joewiak L, Ksiazek A, Kaczor D. (2006). The investigation of Staphylococcus aureus and coagulase-negative staphylococcal nasal carriage among patients undergoing haemogialysis. Microbiol. Res. 161:281287. The investigation of Staphylococcus aureus and coagulase-negative staphylococcal nasal carriage among patients undergoing haemogialysis. Microbiol. Res. 2006; 161:281-287.

[24]. Uemura E, Kakinohana S, Higa N, Toma C, Nakasone N. Comparative characterization of Staphylococcus aureus isolates from Throats and Nose of Healthy Volunteers. Japanese J Infect Dis. 2004; (57):21-24.

[25]. Chigu CO, Ezeronye OU. Antibiotic resistant Staphyloccous aureus in Abia State of Nigeria. Afr J Biotech. 2003; 2(10):374-378.

[26]. Adesida SA, Abioye OA, Bamiro BS, Brai BI, Smith SI, Amisu KO, et al. . Associated risk factors and pulsed field gel electrophoresis of nasal isolates of Staphyloccous aureus from medical students in a tertiary hospital in Lagos, Nigeria. Brazilian J Infect Diseases. 2007; 11(1):63-69.

[27]. Olayemi,OJ, Olayinka BO, Musa AI. Evaluation of antibiotic self-Medication Pattern amongst undergraduate students of Ahmadu Bello University (Main Campus), Zaria. Res. J. Appl. Sci. Eng. Technol., 2010 2(1): 35-38.

[28]. Adegoke AA, and Komolafe AO. Multi-drug resistant Staphylococcus aureus in clinical cases in Ile-Ife, Southwest Nigeria. International Journal of Medicine and Medical Sciences. 2009; 1. (3) pp. 068-072.

[29]. Couto I, Melo-cristino J, Fernades ML. Unusually Large Number of Methicillin-Resistant Staphylococcus aureus Clones in a Portuguese Hospital Dois: 2000; 101016/50, 40-6736(01)08713-5.

[30]. Sapkota AR, Coker ME, Rosenberg Goldstein RE, Atkinson NL, Sweet SJ, Sopeju PO, Ojo MT, Otivhia E, Ayepola OO, Olajuyigbe OO,. Self-medication with antibiotics for the treatment of menstrual symptoms in Southwest Nigeria: a cross-sectional study. BMC Public Health 2010, 10:610. ttp://www.biomedcentral.com/1471-2458/10/610.

[31]. Okeke IN, Aboderin OA, Byarugaba DK, Ojo KK, Opintan JA. Growing problem of multidrug-resistant enteric pathogens in Africa. Emerging Infectious Diseases. 2007, 13:1640-1646.

[32]. Ojo KK, Sapkota AR, Ojo TB, Pottinger PS: Antimicrobial resistance gene distribution: A socioeconomic and sociocultural perspective. GMS German Medical Science. 2008, 3: Doc 26. 
Table 1: Percentage (\%) of Staphylococcus aureus among the participants

\begin{tabular}{|l|l|l|l|}
\hline Subjects & $\begin{array}{l}\text { Sample } \\
\text { number }\end{array}$ & No. positive & $\begin{array}{l}\text { Percentage } \\
(\%)\end{array}$ \\
\hline Group 1 & 60 & 42 & 70 \\
\hline Group 2 & 60 & 49 & 81.66 \\
\hline Total & 120 & 91 & 75.83 \\
\hline $\begin{array}{l}\text { p-value }= \\
0.1355\end{array}$ & \multicolumn{2}{|l|}{} \\
\hline Subjects by Sex & & & \\
\hline Females & 60 & 48 & 80 \\
\hline Males & 60 & 43 & 72 \\
\hline Total & 120 & 91 & 75.83 \\
\hline p-value $=0.2863$ & & \multicolumn{2}{|l|}{} \\
\hline
\end{tabular}

Group 1= Microbiology participants Group 2= Biochemistry participants $P$ values for the combined $=0.1355$ For male and female, $\mathrm{p}<0.2863$

Table 2: Percentage of isolated $S$ aureus from nasal and thumb samples from both study groups.

\begin{tabular}{l|l|l|l}
\hline & No. of sample & Nasal & Thumb \\
\hline Group 1 & 30 each & $80 \%(24)$ & $60 \%(18)$ \\
Group 2 & 30 each & $87 \%(26)$ & $75 \%(23)$ \\
\hline
\end{tabular}

Group $1=$ Microbiology students

Group 2 = Biochemistry students

Nasal $\mathrm{p}<0.488$ (for both groups) Thumb $\mathrm{p}<0.1652$ (for both groups) Nasal/thumb (Gp.1) p $<0.09$ Nasal/Thumb (Gp.2) p $<0.32$

Table 3: Percentage distribution of isolated $S$ aureus in relation to gender

\begin{tabular}{|l|l|l|l|l|}
\hline \multirow{2}{*}{} & \multicolumn{3}{|c|}{ Nasal } & Thumb \\
\cline { 2 - 5 } & M & F & M & F \\
\hline Group 1 & $87 \%(13)$ & $\begin{array}{l}73 \% \\
(11)\end{array}$ & $47 \%(7)$ & $\begin{array}{l}73 \% \\
(11)\end{array}$ \\
Group 2 & $73 \%(11)$ & $\begin{array}{l}100 \% \\
(15)\end{array}$ & $80 \%(12)$ & $\begin{array}{l}73 \% \\
(11)\end{array}$ \\
\hline
\end{tabular}

Group 1= Microbiology Students Group 2= Biochemistry students 
Figure 1: Mean Percentage resistance of Staphylococcus aureus isolates from nasal swabs to various antibiotics

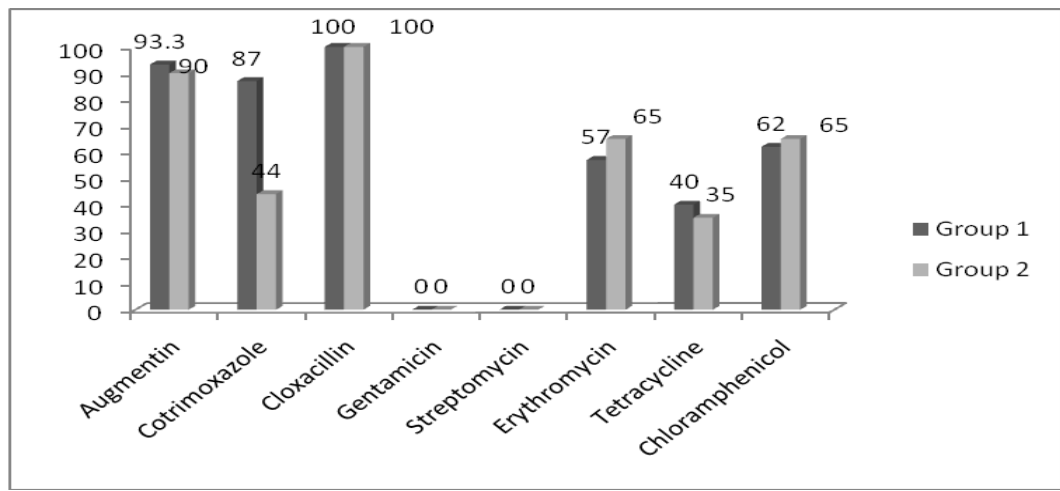

Figure 2: Mean zone of inhibition $(\mathrm{mm})$ by Nasal and thumbprint isolates from group 1 participants to the antibiotics.

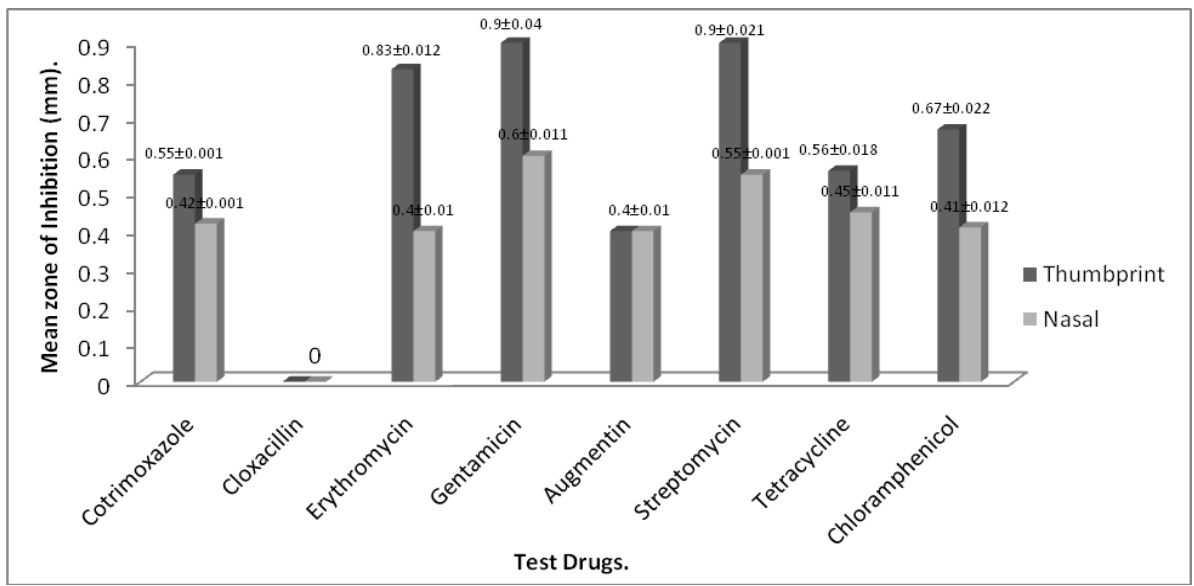

Figure 3: Mean zone of inhibition (mm) by Nasal and thumbprint isolate from group 2 participants to the antibiotics.

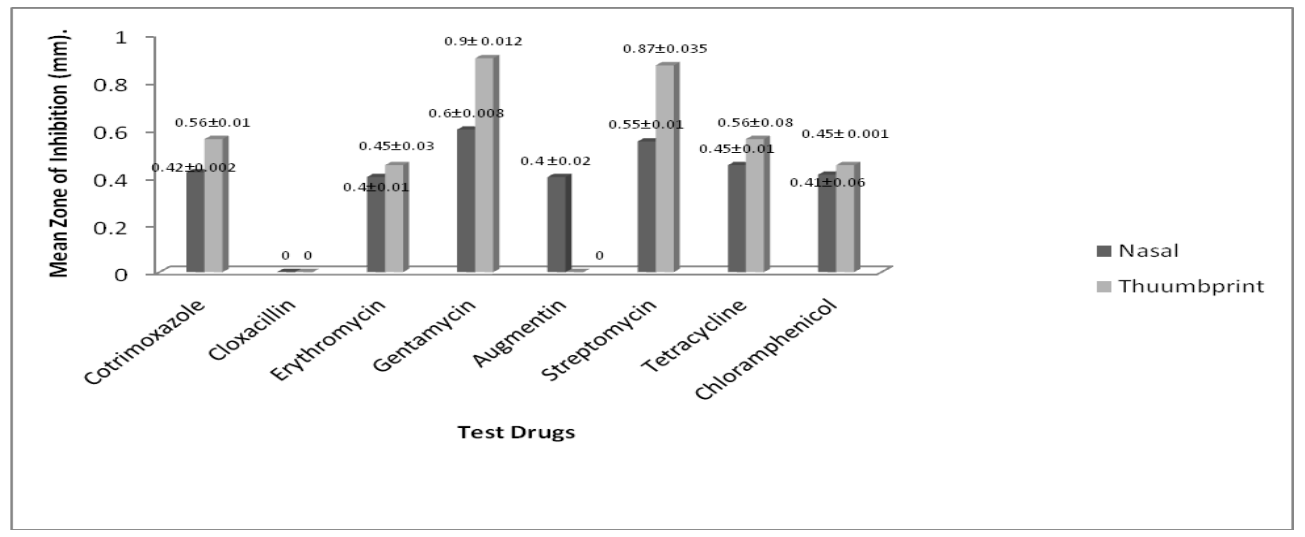

